\title{
Satan's Playground
}

\author{
American Encounters / Global Interactions
}

A series edited by Gilbert M. Joseph and Emily S. Rosenberg

This series aims to stimulate critical perspectives and fresh interpretive frameworks for scholarship on the history of the imposing global presence of the United States. Its primary concerns include the deployment and contestation of power, the construction and deconstruction of cultural and political borders, the fluid meanings of intercultural encounters, and the complex interplay between the global and the local. American Encounters seeks to strengthen dialogue and collaboration between historians of U.S. international relations and area studies specialists.

The series encourages scholarship based on multiarchival historical research. At the same time, it supports a recognition of the representational character of all stories about the past and promotes critical inquiry into issues of subjectivity and narrative. In the process, American Encounters strives to understand the context in which meanings related to nations, cultures, and political economy are continually produced, challenged, and reshaped. 



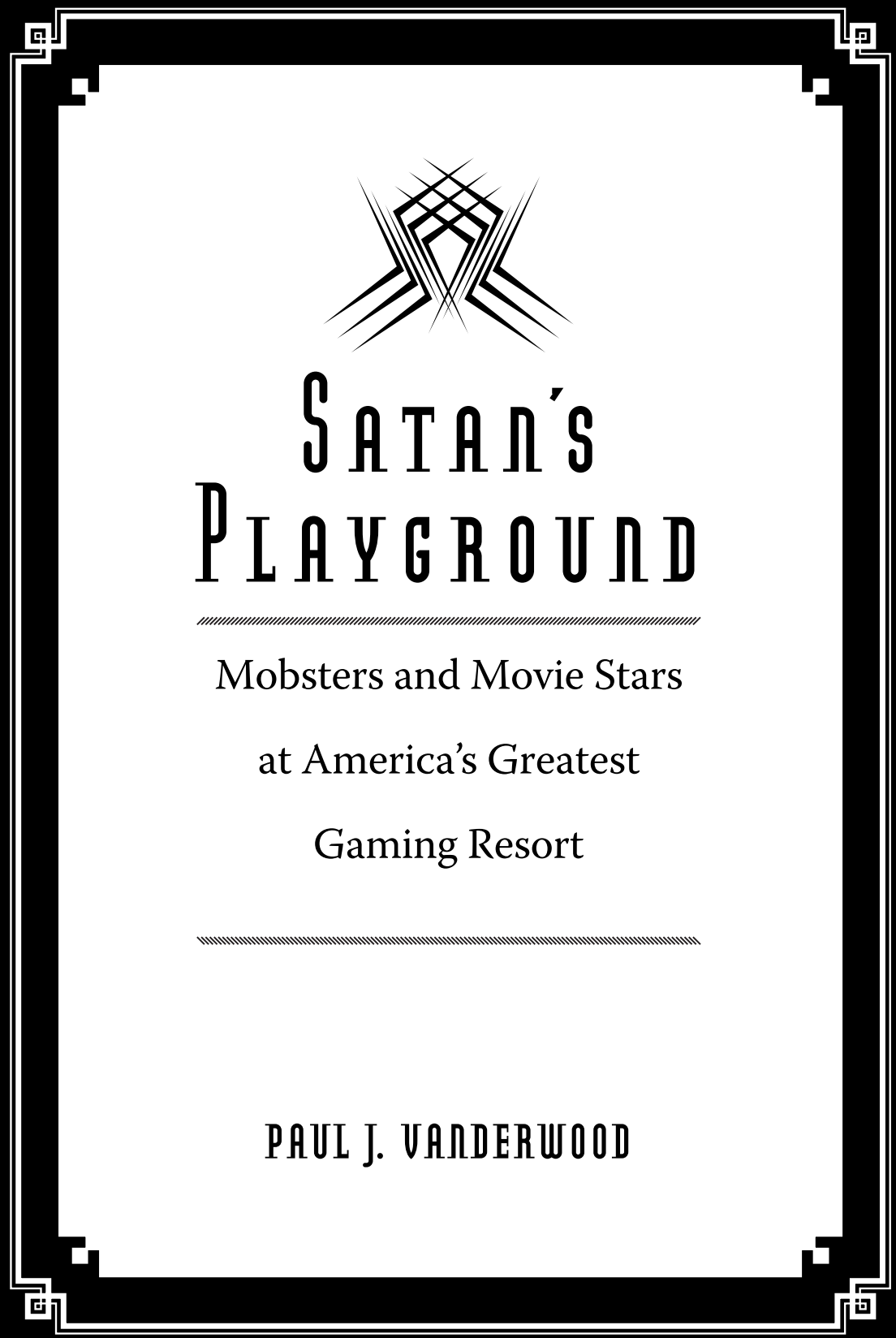

DUKE UNIVERSITY PRESS DURHAM AND IOMDOA 2010 


\author{
(C) 2010 \\ Duke University Press \\ All rights reserved \\ Printed in the United States \\ of America on acid-free paper $\infty$ \\ Designed by Katy Clove \\ Typeset in Warnock Pro by Keystone Typesetting, Inc. \\ Library of Congress Cataloging-in-Publication \\ Data appear on the last printed \\ page of this book.
}


For GLS 
